\title{
On the Role of Logic in Analytic Theology: Exploring the Wider Context of Beall's Philosophy of Logic
}

\author{
A.J. Cotnoir \\ University of St Andrews
}

\begin{abstract}
What is the proper role of logic in analytic theology? This question is thrown into sharp relief when a basic logical principle is questioned, as in Beall's 'Christ - A Contradiction.' Analytic philosophers of logic have debated between exceptionalism and antiexceptionalism, with the tide shifting towards anti-exceptionalism in recent years. By contrast, analytic theologians have largely been exceptionalists. The aim of this paper is to argue for an antiexceptionalist view, specifically treating logic as a modelling tool. Along the way I critically engage with Beall on the role of logic in theology, maintaining that theological inquiry is in some ways disanalogous with other theoretical enterprises.
\end{abstract}

How should considerations of the limits of human reason influence our theological methodology? That is a central question spanning the history of theology, of course. But it is one which is particularly pressing in the contemporary context of analytic theology. What is the role of logic in theology? What principles of logic are open to revision based on theological considerations? These questions - which are raised anew when a dearly held logical principle is challenged - take us deep into the realm of the philosophy of logic. In this essay my aim is to provide some answers to these questions, answers which challenge a stance predominant among analytic theologians.

In his paper, Beall also devotes significant attention to the role of logic in theology. Among Beall's claims: (i) the role of logic in theology is just the same as the role of logic in every other theoretical enterprise - it is the common core of all theoryrelative consequence relations; and (ii) that the validity of ex falso quodlibet (or 'explosion') and the law of excluded middle are theologically open questions. Beall then argues for a Christology which accepts the contradictions that appear to be entailed by Christ's two natures.

I'm largely in agreement with much of what Beall says about (ii). It is worth highlighting that his aim - to argue that a contradictory Christology is both formally viable and philosophically motivated - is very modest. As to whether a contradictory Christology is the best theory of the incarnation, I have some doubts (some of which

Journal of Analytic Theology, Vol. 7, June 2019

10.12978/jat.2019-7.00-51-51021417

(C) 2019 A. J. Cotnoir • (C) 2019 Journal of Analytic Theology 
are expressed in §3.2). But I want to reiterate something I've said elsewhere: ${ }^{1}$ the time is ripe for theologians to explore their (non-classical) logical options.

My main point of disagreement with Beall stems from (i). I want to challenge the idea that the role of logic in theology is as Beall suggests. Theologians should, I argue, think of logical methods as a set of tools for constructing (closed) theories, and not think of logic as a universal foundation for all possible theories.

Within analytic philosophy there is a long-standing dispute over divergent views on the role of logic in theories generally. The dispute is between two factions, between exceptionalists about logic and anti-exceptionalists about logic. I suggest that analytic theology has, as a matter of contingent historical (sociological?) fact, been conducted in a way that is largely one-sided, operating only from within an exceptionalist framework. Analytic theology, then, misrepresents the analytic tradition in the philosophy of logic as having an exceptionalist character. But I also wish to argue that anti-exceptionalism is a promising methodological programme for analytic theology. I outline an anti-exceptionalist conception of the role of logic that is philosophically grounded, coheres better with the larger theological tradition, is more flexible and defeasible, and hence is a better analytical tool.

In $\S 1$, I explain the dispute between exceptionalists and anti-exceptionalists, and gesture at some philosophical reasons in favour of anti-exceptionalism. In $\S 2$, I discuss how analytic theologians have viewed the role of logic, arguing that generally they have been exceptionalists, and provide theological reasons why they should be anti-exceptionalists. In $\S 3$, I critically discuss Beall's own views on the role of logic, suggesting in $\$ 3.1$ two interpretations of Beall on opposite ends of the exceptionalist/anti-exceptionalist spectrum. In $§ 3.2$, I cast some doubt on Beall's identification of FDE as the 'common core'. And in §3.3, I argue that theology is unlike other theoretical enterprises; human rational limitations loom large in theological methodology, and this provides even more reason to be skeptical that we have a firm grip on the absolutely true and universal Logic. In $\S 4$, I sketch an alternative approach to the role of logic, one that still affords a large role for formal methods in theology but precisely because logical theorizing should always be regarded as subject to scrutiny and potential theological revision.

\section{Logic in Analytic Philosophy}

I won't assume that readers are familiar with contemporary analytic philosophy of logic, so in order to contextualize a bit, let me start with a few commonplace distinctions. The first is in metaphysics, between what is necessary (i.e. true in all possible worlds) and what is contingent (i.e. true in only some). This distinction is not to be confused with the semantic distinction between what is analytic (i.e. true in virtue of meaning) versus what is synthetic (i.e. true in virtue of the way the world is - at least in part). And again, these distinctions should be kept clearly separate from the epistemic difference between what is a priori (i.e. known to be true independently

${ }^{1}$ See Cotnoir (2018). 
of experience) versus what is a posteriori (i.e. known to be true based on experience - at least in part). Logical consequence is virtually always agreed to be metaphysically necessary; if an argument is valid it is so necessarily, and if invalid then so necessarily. Similarly, if a sentence is logically true, it is necessarily true; and if a sentence is logically false ${ }^{2}$, then it is necessarily false. But there is much dispute over whether logical inferences are analytic and a priori.

\subsection{Exceptionalism vs. Anti-exceptionalism}

There are two opposing views. In the red corner, the former heavyweight...

Exceptionalism: Logic is special! It is analytic and always known apriori.

The main idea behind exceptionalism is that basic logical laws and inferences are valid because they are analytic. They are thought to be the result of stipulating the rules of certain concepts (the 'logical' ones e.g. negation, conjunction, etc.). Such stipulations implicitly define their concept and hence are constitutive of the meaning of the concept itself. Basic logical laws and inferences are also such that anyone who understands the basic logical concepts knows a priori that they are valid. Anyone who purports to disagree with a logical inference is simply confused (e.g. they must not mean negation when they say 'not'). As a result, logical inferences aren't revisable or subject to scrutiny; no empirical evidence or religious doctrine could ever call them into question. ${ }^{3}$

And in the blue corner, the challenger ...

Anti-Exceptionalism: Logic isn't special! It isn't analytic, and isn't always known apriori.

According to anti-exceptionalism, basic logical laws and inferences are not generally stipulations or constitutive rules governing concepts. One can perfectly well understand the meaning of logical concepts whilst rejecting some of the purported 'rules' that govern its use. Basic logical laws and inferences are not typically justified a priori; the methods of logic are continuous with theoretical methods in science and elsewhere. As a result logic is subject to revision on the basis of abductive considerations like simplicity, explanatory power, unification, fruitfulness, non-adhocness, and fit with evidence. "Logic is in principle no less open to revision than quantum mechanics or the theory of relativity." (Quine 1986, 100)

\footnotetext{
2 NB: And by 'logically false', I don't mean contradictory!

3 Some exceptionalists: Boghossian $(2000 ; 2001 ; 2003)$, Dummett $(1975 ; 1978 ; 1991)$, Peacocke (1987; 1992; 1993), Prawitz (1971; 1977), Read (forthcoming), Tennant (1997; 2007)

${ }^{4}$ Some anti-exceptionalists: Bueno \& Colyvan (2004), Maddy (2000; 2002), Putnam (1969; 1976), Quine (1951 1974; 1986), Priest (2006; 2014), Russell (2015), Williamson (2007; 2013; 2015).
} 


\subsection{In Favour of Anti-Exceptionalism}

A number of arguments have been put forward in favour of anti-exceptionalism. ${ }^{5}$ I won't rehearse them here, but of particular relevance are considerations surrounding the semantic plasticity of logical terms. The idea is that use of basic logical vocabulary is flexible; it can vary without it being immediately clear that the 'deviant' uses are incoherent. Williamson (2007) gives a number of examples. Consider Simon, an expert on vagueness in the philosophy of language who, for theoretical reasons, rejects conjunction elimination. Or consider Peter who agrees with Aristotelian logic that 'All $F$ s are $G$ s' entails that 'there are some $F \mathrm{~s}$ '. Suppose further he (mistakenly) believes that there are no vixens, and hence rejects 'All vixens are vixens'. In both cases we have individuals who deny valid logical principles. But are Simon's and Peter's statements incoherent? Are they incompetent users of the words 'and' and 'all'? Or is it rather that they are coherent and competent speakers of their native language who happen to have slightly odd beliefs?

In the last half of the $20^{\text {th }}$ Century, there has been a massive development of a huge number of non-standard formal logics. For almost any basic logical rule, there is a system violating it. Many of these non-classical systems have been put to fruitful use in attempting to solve difficult philosophical problems. Of course, not all these logics can be correct, or even accurate restricted to their respective applications. But can it really be true that all of these developments involve a deep misunderstanding of logical vocabulary? Another way to put the question: is there exactly one possible theory of the logical concept 'not', such that all other theories must be theories of some other concept? And are the many expert logicians who are proponents of nonstandard logics simply being incoherent, talking complete nonsense, or failing to understand the concepts they appear to employ? If exceptionalism is correct, it would seem so.

\section{Logic in Analytic Theology}

A traditional conception of philosophy's relationship to theology is that of a handmaid to her mistress. "A handmaid is a helper, not a hindrance, and certainly a servant, not a superintendent to her mistress." (Crisp 2009, 41). Correspondingly, there is the instrumental conception of the role of logic in theology according to which logic is always subject to the proper aims, methods, and deliverances of theological inquiry.

Analytic theologians are sometimes accused of wheeling in a much more substantive conception of the role of logic in theology, according to which: ${ }^{6}$

[R]eason alone, or reason and the senses, give us fundamental and general non-trivial knowledge about the world around us that every

\footnotetext{
${ }^{5}$ For an excellent discussion see Hjortland (2017), from which this paper has benefited greatly.

${ }^{6}$ Here, for terminological reasons, I am eliding the differences between 'reason' and 'logic'. But these are not the same thing and should be kept separate in any complete analysis. (Thanks to John Perry for discussion on these issues.)
} 
rational person can understand, or is capable of understanding, and on the basis of which every rational person is able to make sense of the world. Theology, on this view, must conform to reason in order for it to be taken serious as an intellectual discipline. (Crisp 2009,41)

According to the substantive conception of the role of logic, theological inquiry is subject to the norms and constraints of logic; any perceived conflicts with principles of logic must be resolved or dissolved.

Now, this way of carving up the issue mirrors the dispute within philosophy over the role of logic. The instrumentalist conception reflects a broadly antiexceptionalist outlook: logic is subject to scrutiny if in conflict with theological theorizing. The substantive conception reflects a broadly exceptionalist outlook: logic is the bedrock of all rational theorizing, and any theory which attempts logical revision is strictly incoherent.

\subsection{Analytic Theology and Exceptionalism}

Analytic theologians have, by and large, tended toward exceptionalism. I can't consider a wide swath of literature, but a few case studies should make the point.

Consider Swinburne who endorses that human knowers have privileged epistemic access to the logical relations holding between their own beliefs.

Although we have infallible access to the content of our beliefs, we cannot have single beliefs in isolation from other beliefs and other mental states; and, for each belief with a certain content, in order to be that belief it must sustain certain logical relations to the subject's other mental states. Our infallible access is to the web of such states. (2001, 40, emphasis mine)

Swinburne accepts that we have a perfect knowledge of the deductive entailments that constitute our web of beliefs. Perhaps even more strikingly, Swinburne similarly accepts that we also have this privileged access to inductive inferential relationships between evidence and our beliefs.

If science is really a rational enterprise in the sense that certain evidence really does make one hypothesis more probable and another hypothesis less probable, and so there are indeed correct criteria of inductive inference, of what is evidence for what and how strong particular evidence is, there must be principles of probability ... and in particular a priori principles for ascribing intrinsic probabilities.... If there are no such a priori criteria, we should give up studying science, history, and every other subject of university study. (122, emphasis mine) 
The idea here is that correct principles for evaluating and reasoning in accordance with evidence must be knowable a priori, that is knowable independent of any experience. And so our knowledge of such principles is exceptional; it is not on a par - is not of a kind - with our knowledge of other sorts of facts we learn through any sort of experience. They are not subject to revision and any disagreement over them constitutes a rational mistake. ${ }^{7}$

Reformed epistemology is perhaps one of the more well-known frameworks in analytic theological circles, due to the influence of Plantinga. It also appears to be committed to the exceptionalist picture. Crucial to the reformed epistemological perspective is the acceptance of indubitable basic (non-inferential) beliefs. And the validity of certain inferential principles are themselves thought to be properly basic. Consider Plantinga:

Now among these faculties, one of the most important is reason. Taken narrowly, reason is the faculty or power whereby we form a priori beliefs, beliefs that are prior to experience or, better, independent, in some way, of experience. These beliefs include what... we called the deliverances of reason: first of all, the simple truths of arithmetic and logic, such as $2+1=3$ and if all men are mortal and Socrates is a man, then Socrates is mortal. $(2000,146-7)$

Principles of logic (the 'simple' ones, at any rate) are taken to be deliverances of reason. We can be justified in accepting them insofar as the faculty of reason is in fact reliable, which Plantinga clearly believes to be the case.

I am in fact convinced that these sources of belief are reliable. True enough: I realize that I can't give a good non-circular argument for their reliability.... Not even God himself, necessarily omniscient though he is, can give a non-circular argument for the reliability of his ways of forming beliefs. God himself is trapped in the circle of his own ideas. (125)

The final sentence is intended to be provocative. But what is crucial is that logical principles are, in Plantinga's view: a basic belief forming method, a priori, and not subject to (non-circular) arguments for justification or revision.

Though I've given merely anecdotal evidence, I think the exceptionalist presumptions are common enough in analytic theology. But exceptionalism is not required of analytic theologians any more than it is required of analytic philosophers.

\subsection{Theology and Anti-Exceptionalism}

\footnotetext{
${ }^{7}$ Swinburne (2001) again: "Many people defend principles of deductive reasoning that all professional logicians hold to be manifestly invalid. [...] In consequence, there is no incoherence in psychologists reporting that in certain respects many people are irrational." (p. 122)
} 
I want to suggest that anti-exceptionalism is a good methodological programme for analytic theologians. One key reason is the importance of tradition in the theological enterprise. The Christian theological tradition spans millennia; logical systems were revised and developed over the course of many centuries. ${ }^{8}$ We cannot hope to be faithful to such a diverse tradition if we do not allow ourselves the possibility of treating these systems as rational theoretical options, and examining the internal coherence of these systems.

It would be intellectually dishonest to pretend that Aquinas and Barth, for example, were operating within the same conceptual framework, utilising the same logic(s) in exactly the same way. (Indeed, Barth appears to believe that the law of noncontradiction is invalid in theology. ${ }^{9}$ ) It's clear enough that not even Aquinas and Duns Scotus were in agreement over all logical principles. Moreover, it would be uncharitable to claim - as exceptionalists must! - that because they had differing systems one or other of them is conceptually confused, incoherent, or simply talking past one another.

Furthermore, logical systems themselves need to be capable of revision because they can and should be challenged on theological grounds. This isn't a new thought, of course; principles of logic were called into question on purely theological grounds throughout the medieval period. A classic example of the Trinity, which was taken by some to be a counterexample to the validity of expository syllogism. ${ }^{10}$

If a logical system has certain internal commitments that lead to doctrinal heresy or serious conflict with sources of evidence taken to be authoritative (e.g. councils or biblical texts), then we must be able to recognise these commitments and revise them accordingly.

\section{Beall on the Role of Logic}

Apart from the instrumental and substantive conceptions, there is another procedural conception of the role of logic in theology. According to this view logic is required for "establishing the logical connections between different propositions, for distinguishing what I am talking about from what I am not, and whether what I am saying makes sense, or is incoherent." (Crisp 2009, p. 41). Logic, then, is a necessarily unavoidable framework for any inquiry whatsoever; ipso facto inescapable for theology too.

Any reasoning about anything requires the acceptance, the use, of procedural reason. We are continually making judgements of what, given certain assumptions about how the world is, ... is likely to be

\footnotetext{
8 Beall's account of the provenance of 'standard logic' (407) might be misread as suggesting that the accepted logic has been stable since Aquinas. I doubt Beall thinks this, and I certainly don't.

9 "God is a free Lord, not only over the law of non-contradiction, but over his own deity" (Barth 1927, 217). See also Rehnman (2008) for discussion. (Thanks to Jared Michelson for the pointer.)

10 An expository syllogism has singular propositions as both premises (e.g. "The Father is God; God is the Son. So, the Father is the Son"). See Uckelman (2009, ch. 7). (Thanks to Stephen Read here.)
} 
true, and reason is necessary for making or assessing such claims. (Helm 1997, 7)

The procedural conception brings us nearer to Beall's views on the role of logic in theology.

\subsection{Consequence Relations and Universal Logic}

Beall draws a contrast between consequence relations and logic. When we are engaged in a theoretical inquiry about some subject matter, we aim to characterize all the truths of that subject matter. We do this by laying down some accepted truths, and then throwing in all the truths that follow from them. This process of 'closing' our initial truths requires the correct consequence relation (or 'entailment relation') for that theory. Consequence relations are determined from the space of scenarios that the theory considers to be 'possible' (i.e. theoretically live options). This means that consequence relations are theory-relative (because different areas of inquiry recognize different spaces of possibilities). Beall is a 'consequence pluralist',11 and I should note that on this score, Beall and I are in much agreement.

Logic, then, on Beall's view, is the common core of all theory-relative consequence relations. Because it is not theory relative, it is topic-neutral (405). And because it takes as its space of 'possibilities' every theoretically live option (406), its deliverances are necessary in the broadest sense.

One might think that, if the space of possibilities is absolutely unrestricted, this might lead to logical consequence that is unfeasibly weak. But Beall claims, "it's not that 'anything goes' by logic's lights" (407), because logic focuses narrowly on a specific stock of 'logical vocabulary' - the common, foundational, universal core. Beall calls this core vocabulary the 'boolean quartet' containing the usual conjunction $(\Lambda)$, disjunction ( $V$ ), and negation $(\neg)$, but also the more unusual 'nullation' or truth operator $(\dagger)$. (Notably absent is anything like a conditional. ${ }^{12}$ )

The entailment relation governing the boolean quartet, called 'FDE', is logic proper, according to Beall; this logic is common to all theory-relative entailment relations. That is, an argument is logically valid if and only if the premises entail the conclusion according to every (true, theory-relative) consequence relation. This last biconditional invites the following question: which determines which? What is the order of explanation? Is universal logic primary, and so determines the space of possible consequence relations? Or are theory-relative consequence relations primary, and logic is determined simply by looking at their intersection?

The different directions of explanatory dependence are crucial, since the answer to this question will push Beall further toward the exceptionalist or anti-

\footnotetext{
11 The views Beall expresses are clearly derived from his earlier work (with Greg Restall, 2006) on Logical Pluralism. There, consequence relations were called 'logics', whereas now he wishes to reserve the term 'logic' for the universal relation underlying every kind of entailment.

${ }^{12}$ It might seem that the conditional is foundational to reasoning if anything is. For why this is missing, see Beall (2015).
} 
exceptionalist paradigms. On a consequence-first view, what counts as logic is still in principle revisable by new theoretical discoveries. By contrast, if logic is first and determines a priori the constraints on any possible theory, then logic is unrevisable. It might even be that logically valid inferences are analytic, explained entirely by the meanings of the boolean quartet.

Beall doesn't tell us his views on this issue. But he frequently describes logic as 'foundational' or 'at the bottom' of our practices of inquiry. ${ }^{13}$ Such descriptions suggest that he believes logic, and not consequence relations, is primary. That is, for any theoretical enterprise, if it is to count as coherent at all, it must abide by FDE. And if that's the view, here I part ways with Beall. (More on this below.) On the other hand, I'm much more sympathetic to a consequence-first view, except that I think we have been given little reason to think that the resulting logic will be FDE. (Again more in the next section.)

Before moving to these arguments, though, I want to suggest that the more exceptionalist version of Beall's view puts him in a dialectically weak position against his opponents. I think Beall is quite right that contradictory Christology (and nonclassical theology generally) has been almost completely neglected, merely because the majority have simply assumed the law of non-contradiction (or more accurately ex falso quodlibet) as logical bedrock. Beall of course sharply disagrees, but he does so by simply assuming a different set of inferences as logical bedrock. They disagree over basic logical rules, and both parties (qua exceptionalists) believe that anyone who disagrees is conceptually confused or changing the subject. And in the words of the Dread Pirate Roberts, "if there can be no arrangement, then we are at an impasse."14 It might seem - frustratingly, to Beall's opponents - that there are no nonquestion-begging grounds for debate.

Proceduralism about the role of logic points to an obvious truth: theoretical inquiry procedurally requires the use of some logical system. That is, we must close our theories under some kind of consequence relation. But we should be careful to distinguish this very plausible thought with its stronger exceptionalist cousins. While it is true that any theological reasoning requires some logical assumptions, it need not be true that there are some logical assumptions that are required by any theological reasoning. ${ }^{15}$ That is worth saying again: all theological inquiry must endorse some logical framework (or other), but there is no logical framework that all theological inquiry must endorse. Or at least, so I'll argue.

\subsection{Which Entailments?}

13 "Logic plays its universal, foundational role in our theories" (406); "the foundation of all entailment" (407)

${ }^{14}$ Reiner et. al. 2000.

15 Perhaps there are some logical principles that are required of any orthodox theological reasoning, but these wouldn't be secured by the procedural conception. The deliverances of creeds and councils are theological data, and so still theory-first. See also discussion in Pawl's contribution to this volume. 
What is the range of permissible entailment relations? Beall tells us two things: they must be closure relations $(403, \mathrm{fn} 6)$, and they must contain the boolean connectives with FDE as a sublogic (i.e. they must validate at least all FDE inferences).

For a consequence relation $\Rightarrow$ to be a closure relation, it must validate the following meta-rules:

$$
\begin{aligned}
& \text { Reflexivity: } A \Rightarrow A \\
& \text { Monotonicity: If } X \Rightarrow A \text { then } X, B \Rightarrow A \\
& \text { Cut: If } X \Rightarrow A \text { and } X, A \Rightarrow B \text { then } X \Rightarrow B
\end{aligned}
$$

Reflexivity simply claims that the sentences of a theory must be among the consequences of that theory. Monotonicity claims that consequences cannot be 'undone' in light of additional premises. That is, if $X$ is a subset of $Y$, then the consequences of $X$ are among the consequences of $Y$. Cut is a form of transitivity; the consequences of the consequences of $X$ just are the consequences of $X$.

These principles are hard to deny: in order for consequence relations to play their role of drawing out the entailments of a given set of sentences, they seem to be important. And so I'm sympathetic to the thought that consequence relations could, in general, turn out to validate them. But it is worth noting that these each of these principles has been denied by philosophical logicians for a given range of phenomena. ${ }^{16}$ Reflexivity has been denied as a resolution of semantic paradoxes in the theory of truth (Greenough 2001; French 2016); it has been doubted in crosslanguage consequence relations (i.e. 'heterogeneous logics' - see Humberstone 1988), and cross-context consequence relations (Zardini 2014); it has been rejected as a logic for 'begging the question' (Martin and Meyer 1982); it may even be violated in Aristotle's syllogistic (Duncome 2014). Non-monotonic logics have seen tons of theoretical applications across a wide range of philosophical issues (for a start, see Antonelli and Strasser 2016). Cut, too, have been denied as the correct response to vagueness (Zardini 2008), the semantic paradoxes (Ripley 2012), the set-theoretic paradoxes (Weir 2006), and antirealism (Tennant 1987).

And so I don't think we can, in good faith, rule out all such approaches a priori; these are genuine theoretical options that should be decided on by the usual criteria for theory choice. Of course, it may well be true that such consequence relations are false representations of entailment for the target phenomena, but it's too strong to claim in advance that they are outside the bounds of any coherent system. And if they aren't incoherent but ruled out for some other reason, it'd be nice to be told why.

Turning now to the principles of FDE, I want to focus attention on two prime principles. The first is the notoriously controversial principle of double negation elimination.

DNE: $\neg \neg A \Rightarrow A$

${ }^{16}$ Sometimes they are explaining the same phenomena Beall uses ( $(4.2)$ to motivate the rejection of explosion. 
Beall is committed to the claim that every theory must close itself under this rule. So, on the exceptionalist reading, no theory which violates this rule can count as coherent theorizing. But the history of logic and philosophy of mathematics is littered with counterexamples. ${ }^{17}$ The most historically influential - and perhaps the most fully developed - non-classical theoretical programme is constructive mathematics. The consequence relation of constructive mathematics is intuitionistic logic, which denies DNE. It would be absurd to claim that no sustained theoretical reasoning can be carried out unless one accepts DNE, and this puts pressure on the exceptionalist reading of Beall's views.

Second, I want to discuss a potential problem with the De Morgan equivalences.

De Morgan 1: $\neg A \vee \neg B \Leftrightarrow \neg(A \wedge B)$
De Morgan 2: $\neg A \wedge \neg B \Leftrightarrow \neg(A \vee B)$

Intuitionistic logic also famously does not validate the right-to-left direction of De Morgan 1, and so the above considerations apply here too.

But there's another potential issue here. Beall permits a mix of theological gaps and theological gluts (422 fn. 32); his approach to theology is not purely glutty, nor purely gappy. Gluts, recall, are true sentences of the form $A \wedge \neg A$. But given that De Morgan 2 is valid in FDE (and hence valid for Beall's theological entailment), $A \wedge \neg A$ is equivalent to $\neg(A \vee \neg A)$. But this latter sentence states that: it's not the case that $\mathrm{A}$ is either true or false. In other words, this looks like an affirmation that A is a gap. If that's right, then it appears FDE does not have the expressive resources to distinguish between sentences which are gaps and sentences which are gluts.

What does this mean for Beall's theology? Consider the following two sentences:

(1) It is both true and false that Christ is immutable.

(2) It is neither true nor false that Christ is immutable.

We'd expect a contradictory Christology to accept (1) as part of the theory, but deny (2). Unfortunately, since these sentences are logically equivalent, they cannot be distinguished on logical grounds. Perhaps there are theological grounds to distinguish them? It isn't clear how, given that Beall's theological consequence relation will also validate the De Morgan laws.

On a purely gappy approach to theology (Beall and Cotnoir 2017), one never asserts sentences of either form, since they will never be true, and so there is no pressure to distinguish them. On a purely glutty approach (Cotnoir 2018), we deny that there are any gaps, and thus we can interpret sentences like (2) as asserting the falsity of a disjunction of gluts (which is also glutty). Perhaps Beall can also take this line, but if he does he'll have to admit that 'being gappy' is an inexpressible semantic status.

17 Including Dummett's intuitionism, which was a robust philosophical (at times theological) programme. 
This latter issue is related to an objection from contraposition (Anderson 2007): if we have an entailment from $A$ to $B$, then there's an entailment from $\neg B$ to $\neg A$. So, if Christ's divinity entails his immutability, it follows by contraposition that Christ's mutability entails that he is not divine. But that is heretical.

The logic of FDE contraposes in the relevant sense. On a purely glutty approach, however, the consequence relation (called 'LP') does not contrapose; so too on a purely gappy approach (called 'K3'). So, avoiding the mixed strategy would provide yet more insulation from heresy. ${ }^{18}$

Independently of the above considerations, from a theory-first perspective the common core will be determined by the intersection of all true consequence relations. So, unless we are in possession of the true theory for every area of inquiry, our knowledge what's in the common core is at best defeasible, and likely mere conjecture. ${ }^{19}$

\subsection{Whose Logic?}

In this section, I want to address Beall's suggestions that theology is just another kind of theorizing, and so the role of logic in theology is just the same as it is in all theoretical endeavours. For example, he writes "Christian theology is a theory of God, just as macro physics is a theory of the macro-physical world and just as mathematical theories are theories of their respective mathematical phenomena" (403). He claims that the theorist's task is 'to 'complete' the true theory of the given phenomenon. And theology is no different" (404).

But is that right? A recurrent theme across the theological tradition, from Tertullian ${ }^{20}$ to T.F. Torrance 21 , is the idea that God is transcendent, or beyond full human comprehension. And if human conceptual schemes are taken to be limited with respect to God, what about logic?

Recall that logic is primarily delineated by a set of expressions - 'and', 'or', 'not', etc. - the logical vocabulary. But these expressions are directly tied to human natural language. "[T]he target always remains on 'real logical consequence' for our 'real language'." (408) Logic is, for Beall, fundamentally human. ${ }^{22}$

\footnotetext{
18 These problems are reintroduced once we include a contraposable conditional. For extended discussion of these issues, see Cotnoir (2018). Beall's own solution is to claim that the relevant theological consequence relation fails to contrapose even though FDE does. The idea is that, though divinity entails immutability and humanity entails mutability (402), we do not have the entailment from mutability to non-divinity. But again, these problems will just re-emerge if our theological consequence relation permits natural conditional reasoning about God.

${ }^{19}$ For what it's worth, I think it's a live possibility that the common logic to all true theories could turn out to be classical!

20 "His nature is different from the condition of all things." (On the Flesh of Christ, ch. 3). http://www.newadvent.org/fathers/0315.htm

21 "He nevertheless refuses to be understood ... from within the conceptual framework of our natural thought and language." (Torrance 1969, 208)

${ }^{22}$ Compare Swinburne: "[L]ogical necessity is at root a feature of actual human sentences and how they are used. It governs language, and not the world" $(1994,96)$. For a much more in-depth discussion
} 
But can our real language accurately and completely characterize the subject of theological inquiry? Here's a reason to think it can't. If the subject matter of theology is a rational agent, then presumably that agent has a practice of inferring. And it is an assumption of much theology that God is personal, with a mental life governed by reason and engaged in inferential practices. Many theologians believe such a mental life is not epistemically open to us (absent divine revelation). This leaves a gap between the consequence relation that is 'correct enough' for human theories about God, and the 'absolutely true' logic of divine thought. I don't mean to suggest that Beall is confusing these two. But if the view he is advancing is that all rational inquiry (including God's) must be governed by FDE, then we run the risk of objectionable anthropomorphism.

To be clear, I am not claiming that theological inquiry is 'beyond the bounds of $\operatorname{logic}^{\prime 23}$ or any such thing. Theology is fundamentally a form of human inquiry, and so presupposes our linguistic forms and norms of reasoning. My only point is that theologians are right to recognize that these forms and norms place us squarely within a conceptual scheme that God may not share. ${ }^{24}$

There's a fundamental disanalogy, then, between theology and other human theorizing. When we seek out an appropriate consequence relation for other target phenomena, we don't antecedently assume that the object of that inquiry transcends our conceptual scheme in important ways. Nor do we have to grapple with the possibility that the target's perfectly accurate self-understanding may be at odds with our own best theory.

If all the familiar logical systems are creaturely entities tied to human languages and concepts, God could have his own unique form of logic. Even if God were, as Plantinga claims, 'trapped' a circle of his own ideas, he certainly is not trapped in ours.

\section{Logic as a Modelling Tool}

It seems then that logic is anti-exceptional - that is, broadly continuous with science - and yet its role in theology importantly disanalogous from its role in other scientific inquiry. How can we accommodate both? In this section, I want to briefly sketch a promising anti-exceptionalist picture (albeit not the only one) of the role of in analytic theology. This picture is that consequence relations are tools for modeling. ${ }^{25} \mathrm{Formal}$ systems are modelling constraints placed on a particular theology. Those constraints are defeasible, revisable, and subject to typical criteria for theory choice.

Better models will be simpler, more unified, have more explanatory power, and cohere better with the 'data' (be that the ecumenical creeds, dogmas from

about the relation between formal consequence relations and natural language, see Cotnoir (forthcoming). See also Glanzberg (2015) for related ideas.

${ }^{23}$ A complaint Beall (415) makes against Dahm's (1978) position.

${ }^{24}$ Contra Anderson and Welty (2011), who give an extended argument that the laws of our familiar (human) logic are in fact thoughts in the mind of God.

${ }^{25}$ See especially Shapiro 2014, §2.5. See also related discussion in Cook 2010. 
councils or confessions, or the biblical texts). This flexibility allows for alternative systems of thought from across the theological tradition to be modelled, giving us a guide to their internal coherence and explanatory purchase. Moreover, we can achieve this while paying careful attention to the distinction between our limited human understanding of God and God's unlimited self-knowledge.

\subsection{The Limits of Modelling}

The idea of modelling comprises three key components: the theory, the mathematical models, and the target phenomena. Expressions in the language of the theory are mapped onto ('denote') parts of a mathematical structure. That structure is intended to represent the target phenomena, based on the assumption that the mathematical structures are similar (isomorphic, homomorphic, etc.) to the structures present in the phenomena. ${ }^{26}$ So, theories use models to represent by exploiting structural similarities; models and the reality they represent share relevant properties.

It is worth noting that there are already some key limitations to modelling which take us further away from the exceptionalist conception of logic. First, modelling typically proceeds by abstraction in the sense that only certain important aspects of the phenomena are intended to be modelled, without the constraint that every aspect of the phenomena be incorporated. So when building models there will always be some level of incompleteness of the theoretical story. Second, models are idealisations in the sense that they are intentionally ignore complications and so sometimes produce unintended artefacts which are known to be false or inaccurate. Even in the presence of such artefacts, still the model will be correct in what it intends to affirm. This approach is broadly continuous with usual theoretical practices in the sciences and other disciplines - logic isn't special. ${ }^{27}$

But if theology isn't just another theoretical enterprise exactly like the others, then what is the relevant difference, according to the logic-as-modelling view? There are at least two possible sources of disanalogy.

The first disanalogy between theology and the sciences is that the 'target phenomena' of theology is a reasoner whose thoughts are beyond our conceptual repertoire. Thus, the logical system we are using to model God need not be a model of God's logical system. One might use models to attempt to go further: one might try to model God's mental life by assigning (representations of) mental entities to parts of a theology in order to represent God's logic. Such a theological inquiry would represent a human model of God's mental life, which may be more or less accurate but always an incomplete approximation. But we should not confuse the two distinct things: the correct logic for human inquiry into the divine vs. the correct logic for divine inquiry. We may have no access to the latter. And logic-as-modelling does not assume that the correct consequence relation for human theorising about God is the consequence relation that God uses in his own mental life.

\footnotetext{
${ }^{26}$ Modelling is, in effect, building a measurement system. See Scharp 2013, §7.2.

${ }^{27}$ See Bonevac 2012 for discussion of the relation between modelling and analogical predication.
} 
A second main disanalogy between theology and the sciences: recall that modelling is based on similarities. Similarities are symmetric: if $x$ is similar to $y$ in some respect, then $y$ is similar to $x$ in the same respect. As a result, the presumption of structural similarity requires that the mathematical structure and the target phenomena have the relevant properties in the same way. That is, not only is the model like the phenomena, but the phenomena is like the model. ${ }^{28}$ In the case of theology, this assumption runs up against a problem. Not everyone believes that God can share substantive properties with creatures; many theologians from across the tradition have thought that predicating any creaturely property of God will fail to be univocal. So when we say that God is good, we mean something akin to human goodness; or when we say God is wise, we don't mean human wisdom, but a kind of wisdom that is appropriate to God's own being. (Traditionally in theology this have been referred to as 'analogical predication'. From the perspective of contemporary cognitive science and linguistics, however, analogical predication and reasoning are largely rooted in a form of structure mapping much like modelling, and is based on presupposed similarity. ${ }^{29}$ )

For theologians of this stripe, we can easily tweak the modelling picture by suggesting that theological models represent metaphorically. One key difference between analogy and metaphor is that metaphors typically aren't symmetric. ${ }^{30}$ Consider the following two claims:

(3) My butcher is a surgeon.

(4) My surgeon is a butcher.

The two metaphors are asymmetric in that they attribute different properties to their targets based on a prior understanding of the source. On this perspective, then, theological models can represent God, but the means of representation are such that the underlying properties grounding the analogy are not taken to be identical. This is only a sketch, but a fuller version might offer grounds for the view that theological claims can succeed in correct representation without having to resort to univocal predication.

The anti-exceptionalist conception of logic allows us to recognise of the limits of human reason, and hence to affirm the extent to which our own thoughts about God run up against boundaries to our understanding. On a logic-as-modelling view, theological inquiry is limited by our humanity and is always subject to revision and refinement.

\subsection{Avoiding Relativism}

\footnotetext{
28 See Bonevac 2012 for a discussion of the relation between similarity and analogical predication.

29 The locus classicus is Gentner 1983.

30 See Gentner et. al. 2001.
} 
One might suspect there is a danger lurking behind anti-exceptionalism: the spectre of relativism. Logical relativism is a view that goes back to the beginnings of analytic philosophy, particularly to Carnap.

According to Carnap (1934), questions regarding the correctness of a logic only make sense relative to a particular linguistic framework - they are internal questions. Any external questions regarding the correct choice of frameworks cannot arise. Such questions are purely pragmatic and hence depend only on the goals and aims of the language users. Moreover, according to the relativist, there is no purely external perspective in which the objective correctness of a logic can be established, as this would have to be formulated within some linguistic framework, with its own internal logical system.

But merely adjudicating internal questions within a theological system cannot be the only role of logic in systematic theology. ${ }^{31}$ While it may be true that many questions presuppose a system and are hence internal to the system, we should categorically reject the contention that meaningful external questions cannot arise. And the theory-first approach does not deny that there is a 'common core' logic in which to adjudicate such questions. Presumably, for any pair of rival consequence relations, we can find a common setting. The theory-first perspective simply denies that the final universal logic - what is common to all theories - can be decided antecedently to the hard work of theory building.

Comparing the value of systems is a crucial part of the theological task. Some inferential constraints are objectively better than others, even if that 'betterness' cannot be known a priori and is always subject to revision. The abductive methodology - applying the criteria of theory choice: simplicity, unity, explanatory power, fit with the data - allows anti-exceptionalists to judge (theo)logical systems on their overall strengths and weaknesses. We can make objective comparisons on the relative value of various systems without falling into the danger of relativism.

\section{Conclusion}

Analytic theologians have typically accepted exceptionalism about logic, and have frequently afforded a large role to logic in theology on that basis. By contrast, contemporary dogmatic theologians are more likely to reject exceptionalism about logic, and afford it a minimal role in theology on that basis.

But stemming from the analytic philosophical tradition, a third option presents itself: reject exceptionalism about logic and yet afford a large role for the use of formal methods in theology. The use of logics - many logics with rival commitments - is a valuable tool for measuring coherence, important entailments, and inferential connections. A dizzying variety of formal techniques have been developed in the last century; in many ways the progress in the discipline of logic in $20^{\text {th }}$ Century is rivalled only in the late Medieval period. These new techniques have proved extremely valuable in philosophical inquiry, and there is every reason to think some of these

${ }^{31}$ One wonders whether dogmatic theology - in an effort to avoid any semblance of exceptionalism has at times fallen into a tacit logical relativism. 
insights can play a key role - a flexible, revisable, and defeasible role - in theology as well. This is a vision for analytic theology that Beall and I share.

But we needn't expect epistemic 'fixed points', foundational bedrock, or universal principles of reason that are immune to revision. Humans are cognitively limited in a way that makes the object of theological inquiry beyond its ken; and this should remind us that the logical consequence relation for theological inquiry will always be at best correct for human thought about the divine. Capturing the full truth about God - God as he knows himself - is an unachievable aim. This need not force us into a relativism where only by presupposing entire frameworks can meaningful questions be raised. Nor should we assume that, because our theoretical inquiry employs logical resources, God's must be constrained by these resources too. ${ }^{32}$

32 Thanks to the audience at the University of St Andrews Theology seminar for discussion of some of these ideas, especially Jonathan Lett, John Perry, Alan Torrance, Andrew Torrance, Brendan Wolfe, and Judith Wolfe. Also many thanks to Tim Baylor, Ole Hjortland, Kevin Scharp, and Jared Michelson for conversations around these topics over the last few years. Finally, I am most grateful to Jc Beall, who devoted countless hours and unending effort training me in logic, only to have his presumptuous young student disagree with him! I'm very glad for this opportunity to engage with his philosophical (indeed, theological!) research. 


\section{Bibliography}

Anderson, James. 2007. Paradoxes in Christian Theology. Paternoster.

Anderson, James and Greg Welty. 2011. "The Lord of Non-Contradiction: An Argument for God from Logic." Philosophia Christi 13 (2): 321--338.

Barth, Karl. 1927. Christliche Dogmatik im Entwurf. C. Kaiser.

Beall, Jc. 2015. "Free of Detachment: Logic, Rationality, and Gluts." Noûs 49 (2):410423.

Beall, Jc and A. J. Cotnoir. 2017. "God of the gaps: a neglected reply to God's stone problem." Analysis 77(4): 681-689.

Beall, Jc and Greg Restall. 2006. Logical Pluralism. Oxford University Press.

Bueno, Otavio and Mark Colyvan. 2004. "Logical Non-Apriorism and the Law of NonContradiction." In The Law of Non-Contradiction, edited by Graham Priest et. al. Oxford University Press.

Boghossian, Paul. 2000. "Knowledge of Logic." In New Essays on the A Priori edited by Paul Boghossian, Clarendon Press. . 2001. "How are objective reasons possible?" Philosophical Studies 106: 1-40. . 2003. "Blind reasoning." Proceedings of the Aristotelian Society 77: 225-248.

Bonevac, Daniel. 2012. "Two Theories of Analogical Predication." Oxford Studies in the Philosophy of Religion 4: 20-42.

Carnap, Rudolf. 1934. Logische Syntax der Sprache, Springer-Verlag; expanded English translation as The Logical Syntax of Language. Routledge.

Cook, Roy. 2010. "Let a thousand flowers bloom: A Tour of Logical Pluralism." Philosophy Compass 5(6): 492-504.

Cotnoir, A.J. 2018. "Theism and Dialetheism." Australisian Journal of Philosophy, 96 (3): 592-609

. Forthcoming. "Logical Nihilism". In Pluralisms in Truth and Logic, edited by Nathan Kellen et. al. Palgrave Macmillan.

Crisp, Oliver. 2009. "On Analytic Theology." In Analytic Theology: New Essays in the Philosophy of Theology edited by Oliver Crisp and Michael Rea. Oxford University Press. 
Dahms, John. 1978. “How Reliable is Logic?” Journal of Evangelical Theological Society. 21 (4): 369-380.

Dummett, Michael. 1975. "The Justification of Deduction." Proceedings of the British Academy 59: 201-231.

. 1978. “Is Logic Empirical?” Truth and Other Enigmas.

.1991. "The Logical Basis of Metaphysics." Harvard University Press.

Duncombe, Matthew. 2014. "Irreflexivity and Aristotle's Syllogisms." The Philosophical Quarterly 64 (256): 434-452.

French, Rohan. 2016. "Structural Reflexivity and the Paradoxes of Self-Reference." Ergo 3: 113-131.

Gentner, Dedre. 1983. "Structure-mapping: A Theoretical Framework for Analogy." Cognitive Science 7: 155-170.

Gentner, Dedre. et. al. 2001. "Metaphor is Like Analogy." In The Analogical Mind: Perspectives From Cognitive Science, edited by Centner, D. et. al. MIT Press.

Glanzberg, Michael. 2015. "Logical Consequence and Natural Language." In Foundations of Logical Consequence, edited by Colin R. Caret and Ole T. Hjortland. Oxford University Press.

Greenough, Patrick. 2001. "Free Assumptions and the Liar Paradox." American Philosophical Quarterly 38 (2): 115-135.

Helm, Paul. 1997. Faith and Understanding. Eerdmans.

Hjortland, Ole. 2017. "Anti-Exceptionalism About Logic." Philosophical Studies, 174 (3): 631-658.

Humberstone, Lloyd. 1988. "Heterogeneous Logic." Erkenntnis, 29 (3): 395-435.

Maddy, Penelope. 2000. Naturalism in Mathematics, Oxford University Press. . 2002. "A Naturalistic Look at Logic." Proceedings and addresses of the American Philosophical Association, 61-90.

Martin, E. P.; Meyer, Robert K. 1982. "Solution to the P-W Problem." Journal of Symbolic Logic 47 (4): 869-887. 
Peacocke, Christopher. 1987. "Understanding Logical Constants: a Realist's Account.” Proceedings of the British Academy 63: 153-200. 1992. A Study of Concepts. MIT Press.

. 1993. "How are a Priori Truths Possible?" European Journal of Philosophy 1: 175-199.

Plantinga, Alvin. 2000. Warranted Christian Belief. Oxford University Press.

Putnam, Hilary. 1969. “Is logic empirical?” Boston Studies in the Philosophy of Science. . 1976. "The logic of quantum mechanics." Mathematics, Matter and Method, Cambridge University Press.

Prawitz, Dag. 1971. "Ideas and results in proof theory." In Proceedings of the 2nd Scandinavian Logic Symposium, edited by J. E. Fenstad. North-Holland.

. 1977. "Meaning and proofs: on the conflict between classical and intuitionistic logic." Theoria 43: 2-40.

Priest, Graham. 2006. Doubt Truth to be a Liar. Oxford University Press.

. 2014. "Revising logic." In The Metaphysics of Logic, edited by P. Rush. Cambridge University Press.

Quine, W. V. O. 1951. “Two Dogmas of Empiricism.” Philosophical Review 60: 20-43. 1974. "The Roots of Reference." LaSalle. 1986. Philosophy of Logic, 2nd edition. Harvard University Press.

Read, Stephen. Forthcoming. "Anti-Exceptionalism About Logic.” Australasian Journal of Logic.

Rehnman, Sebastian. 2008. "Does it matter if Christian doctrine is contradictory? Barth on logic and theology." In Engaging with Barth: Contemporary Evangelical Critiques edited by David Gibson and Daniel Strange. T\&T Clark.

Reiner, Rob et. al. 2000. The Princess Bride. MGM Home Entertainment.

Ripley, David. 2013. "Paradoxes and Failures of Cut." Australasian Journal of Philosophy, 91(1):139-164.

Russell, Gillian. 2015. "Metaphysical Analyticity and the Epistemology of Logic." Philosophical Studies, 171 (1): 161--175 
Scharp, Kevin. 2013. Replacing Truth. Oxford University Press.

Shapiro, Stewart. 2014. Varieties of Logic. Oxford University Press.

Strasser, Christian; Antonelli, Aldo. 2016. "Non-monotonic Logic." In The Stanford Encyclopedia of Philosophy, edited by Edward N. Zalta. $<$ https://plato.stanford.edu/archives/sum2018/entries/logicnonmonotonic/>

Swinburne, Richard. 2001. Epistemic Justification. Oxford University Press. 1994. The Christian God. Clarendon Press.

Tennant, Neil. 1987. Anti-Realism and Logic: Truth as Eternal. Oxford University Press. 1997. The Taming of the True. Oxford University Press.

. 2007. "Inferentialism, logicism, harmony, and a counterpoint." In Essays for Crispin Wright: Logic, Language, and Mathematics, vol. 2, edited by A. Miller. Oxford University Press.

Torrance, T. F. 1969. Theological Science. T\&T Clark.

Uckelman, Sara L. 2009. Modalities in Medieval Logic. PhD Thesis. University of Amsterdam.

Weir, Alan. 2016. "Is it too much to ask, to ask for everything?" In Absolute Generality, edited by Agustín Rayo and Gabriel Uzquiano. Oxford University Press.

Williamson, Timothy. 2007. The Philosophy of Philosophy. Blackwell. . 2013. “Logic, metalogic and neutrality." Erkenntnis 79(2): 211-231.

. 2017. "Semantic paradoxes and abductive methodology." In The Relevance of the Liar, edited by Bradley Armour-Garb. Oxford University Press.

Zardini, Elia. 2008. “A Model of Tolerance.” Studia Logica 90 (3): 337-368.

Zardini, Elia. 2014. "Context and Consequence: An Intercontextual Substructural Logic." Synthese 191: 3473-3500. 